\title{
Lone mothers' time allocations: choices and satisfactions
}

Anh T. Le and Paul W. Miller

\begin{abstract}
This paper uses the 2006 Australian Time Use Survey to examine the allocation of time to personal care, employment-related activities, home duties, leisure and child care of lone mothers, in comparison to the time allocations of single women, women in childless couples and partnered mothers. Both primary and secondary time allocations are considered. The satisfactions that women report concerning their current time allocations are also analysed. The time use and satisfaction data are described using both tabulations and multiple regression methods. Lone mothers are shown to have similar time allocations as the other types of households, even though they have different financial and time resources. This raises the concern that lone mothers' desire or need to maintain such time allocations may lead to task overload. Consistent with this, lone mothers are found to be less satisfied with the way they allocate their time than single women and partnered mothers. The tensions associated with time use among lone mothers discussed in the literature are real, and important.
\end{abstract}

Keywords: time allocations, child care, lone mothers, satisfaction, well-being 


\section{Introduction}

In many Western countries, including Australia, the number of lone parent families has increased considerably in recent times. Data from the Australian Bureau of Statistics (ABS 2007) show that in 1986 there were around 311,800 lone parent families with young (under 15 years of age) children in Australia. These represented 14 per cent of all families with young children. By June 2005 the number of lone parent families with young children had increased to $463,000,21$ per cent of all families with young children. At June 2011 lone parent families with young children under 15 years of age numbered 491,000, which is also 21 per cent of families with young children (ABS 2011).

The links between the growth in lone parent families in Australia and the welfare system have been examined by Gregory and his colleagues (2008). The care lone parents provide to their children has also been investigated, as 'Without a partner, it is difficult for single mothers to provide the time and attention that children receive in two-parent homes' (Kendig \& Bianchi 2008: 1228). Craig and Mullan (2012) broadened the scope of this type of inquiry though examination of the child care time of lone mothers and mothers in couple families, and by providing comparisons across Australia, the United States, France and Denmark, countries described as having '...differing normative ideals about mother-care, and policy approaches to work-family reconciliation and to employment activation of lone mothers' (Craig \& Mullan 2012: 512). In overseas research there has also been examination of how lone parents balance their time use across child care, household work and employment, and the so-called work/family role strain among lone parents. The latter topic has led to consideration of satisfaction with specific time allocations, and to examination of the overall levels of happiness of lone parents in comparison to other family types.

If lone parents react to the work/family role strain by providing less child care, and child care is important for the future economic and social success of their children, then addressing the time constraint through welfare policy, or at least reversing some of the more recent changes in this regard in Australia, may have merit. As discussed by Summerfield and colleagues (2010), the changes over 2006 to 2008 to income support eligibility requirements, known as the Welfare to Work reforms, aimed to increase the rate of workforce participation of sole parents, taking into account their caring responsibilities. Yet while these reforms may have led to greater workforce involvement, they may not have necessarily have resulted in an improved income position, or overall level of well-being. As Summerfield and colleagues (2010: 76) note:

the key to reducing welfare dependency for single mothers is in creating an infrastructure to support mothers in the workforce and increase fathers' involvement in the care of their children, whether or not they are separated. The effect of these reforms, however, is to increase the risk of women and children experiencing poverty in the short to medium term after separation, with little guarantee they will prosper financially in the long run. 
In this context, it is also important to consider time uses other than child care and employment, as lone parents may face different trade-offs from those of other groups. For example, in couple families with children, the main trade-off for the mother may be between market work and child care, whereas for lone mothers the main trade-off may be between leisure and child care. To the extent that individuals place different valuations on time allocated to leisure, child care, market work and other activities, the time pressures that lone mothers face may result in a lower quality of life. An assessment of this can be gained through study of satisfaction with the overall allocation of time.

Thus, in this paper we provide a detailed examination of the time uses of lone mothers in Australia to show how they balance their time allocations across child care, home duties, employment-related activities and leisure. Comparisons are provided with partnered mothers, women in childless couples, and single women. Both primary and secondary activities are examined. The study of secondary activities is important, as it enables an assessment of whether lone mothers need to multi-task more extensively than women in other household types in order to cope with the demands on their time associated with being both a bread-winner and a carer of children. Self-reported satisfaction with time allocations are then examined to ascertain if differences in time allocations across household types are associated with different levels of satisfaction. The analysis of the impact of both primary and secondary activities in this regard should further our understanding of the sources of any work/family role strain.

\section{Literature review}

Lone parents have disadvantaged positions in society. In Britain, for example, many do not work (Brannen et al. 1997), and among those that do work there is a disproportionate representation in the lower levels of the labour market, such as clerical and retail jobs, where pay rates are well below the average female rate of pay (Bradshaw \& Millar 1991). As well as these economic disadvantages, lone parents appear to face problems with task-overload, job tension, social life, and arguments with their ex-spouses (Kelly \& Voydanoff 1985; Richards 1989; Richards \& Schmiege 1993).

Lone parents have multiple roles, and so face different pressures compared to other types of households, such as limited human resources, less emotional support, less assistance with household tasks and child care, less time available for social activities, and reduced participation in community life (Smith 1980). As Kendig and Bianchi (2008: 1229) note 'Researchers have hypothesised that single mothers experience a time deficit as a consequence of competing demands that limit the time they have available to care for children'. Nevertheless, studies of the time lone parents allocate to child care have often reported that they do not differ appreciably from partnered mothers in this regard (see, for example, Craig (2005) and Craig \& Mullan (2012) for evidence for Australia and Kendig \& Bianchi (2008) for evidence for the United States) or even that lone parents 
allocate more time to child care than their married counterparts in many circumstances (see Kalenkoski et al. (2007) for evidence for the United States and United Kingdom, as well as Connelly \& Kimmel (2007)).

The desire among lone parents to preserve time with children may lead to task overload. Bell and colleagues (2005) explored the tensions that can arise between time allocations to child care and paid employment for lone parents in England and Wales, and showed how these depend on the attitudes and motivations of the individual concerned. The number of time use activities considered in comparisons between lone-parent families and two-parent families was broadened by Sanik and Mauldin (1986). Their American study illustrated that employed lone mothers allocated less time to household tasks, personal care and recreation than employed partnered mothers, non-employed lone mothers and non-employed partnered mothers. One of the possible approaches for lone mothers to reduce their workloads is to make use of outside services, such as child care services and food services. In reality, lone parents might be constrained in their access to such services by their relatively weak financial situation. ${ }^{1}$

Folbre and colleagues (2005) provided a superior analysis of how lone parents devoted time to child care in the United States, by subcategorising it into active care and passive care, where these measures were from the child's point of view. Hence, active care of a child could involve the parent or another adult. ${ }^{2}$ They estimated regression models which showed that both lone parents and two-parent families provided similar active care time to their children. However, lone parent families spent around 25 per cent less time than two-parent families in providing passive child care, though this might be explained by the fact that in their sample children in lone parent families were, on average, slightly older than those in two-parent families.

Similarly, Craig (2005) reported that Australian lone mothers do not commit to longer working hours than partnered mothers, and lone mothers provide about the same amount of time to child care as a primary activity as partnered mothers, and more time than partnered mothers in this regard when secondary time allocations are taken into account. When analysed from the perspective of the child, so that the care of the father in couple families is also taken into consideration, children in lone parent families only received a few minutes less physical care, and only 13 minutes a day less interactive care as primary or secondary activities, when compared to children in couple families. Thus, Craig's (2005) results suggested that the caring function in lone parents' families is more important than their earning function.

The different time allocations of lone mothers have been shown to be associated with a stressful environment that can be harmful to family well-being (Sanik \& Mauldin 1986; Burden 1986). Burden (1986), for example, found that lone mothers were at high risk for high levels of job/family role strain. This strain decreased the physical and emotional well-being of lone mothers due to the 
three risk factors they were exposed to, namely marital status (single), sex (female) and parental status (parent), respectively. They had higher chances of increased depression and decreased life satisfaction.

Burden (1986) also compared the level of job satisfaction of lone mothers in the United States to that of single male parents and married parents. It was reported that the high level of job-family role strain experienced by lone mothers does not adversely affect their workplace behaviour, and lone mothers scored the highest in job satisfaction compared to other categories (married mothers, married fathers and lone fathers). As well as job satisfaction, the level of satisfaction with aspects of the allocation of time has been examined, though study of lone parent households has not been a major part of this research. For example, Benin and Agostinelli (1988) examined husbands' and wives' satisfaction with the division of household labour as part of an empirical investigation into the way decisions on the allocation of time are made within the household (via a minimal participation model, an equity model, or an exchange model). Piña and Bengtson (1993) reported that the division of household labour affects a wife's happiness through the degree to which she perceives her husband as providing appropriate emotional and instrumental help. Lennon and Rosenfield (1994) found that women's contribution to family resources and their alternatives to marriage influenced their assessment of fairness in the division of household labour. Baxter and Western (1998) showed that gender role ideology and the male spouse's involvement in household activities, especially in the tasks that are usually more likely to be undertaken by women, were associated with higher levels of satisfaction with domestic work arrangements among women.

This type of analysis has been extended to comparisons between family types by Le and Miller (2013), though this study was confined to comparisons of couple families with and without children. In particular, Le and Miller (2013) linked satisfaction with the allocation of time to the degree of inequality in time allocations within the household in order to enhance understanding of whether the expectations partners have in mind when making time allocation decisions have any bearing on reported well-being. They reported that a higher degree of inequality in the division of time in the family unit affected the satisfaction with the current allocation of time of both husbands and wives in couple families without children. Such inequality did not affect the extent to which either husbands or wives in couple families with children were satisfied with their current time allocation. These contrasting results were argued to be due to the underlying patterns of time allocations in these family units, such that children are associated with an expectation of differences in time use.

To sum up, time allocation may have a significant effect on the quality of the families' lives because it affects the stress experienced in life roles, and thus affects general well-being. Hence, it is important to understand the ways that single mothers utilise their time and how their time use varies from that of other household types. Furthermore, by looking at the links between time allocations 
and satisfaction data, it may be possible to identify the job/family role strains that lone parents experience which impact most on their well-being. This is consistent with the suggestion of Kendig and Bianchi (2008: 1239) that

Our understanding of the importance of maternal time allocation and its variation by maternal marital status and living arrangements would be enhanced if we could add information on child outcomes and the health and well-being of mothers and children to the time expenditure data we utilise in this work.

\section{Data}

The analyses presented below are based on the 2006 Time Use Survey (TUS) (ABS 2006a). This survey was conducted by the Australian Bureau of Statistics to collect information about the way people allocate time to different kinds of activities during a specified period. A total of 3,626 households were included in the survey, covering 3,793 families, and 6,902 adults completed the survey instrument. Information about the way these adults spent their time over a two-day period was collected, yielding a total of 13,617 diary days. As well as information on time allocations, the survey collected data on a range of other matters, including family status, age, education, labour force issues, community participation, and satisfaction with time use.

The data cover lone parents, singles, people living in couple families with children (dependent or non-dependent) and those living in couple families with no children present. All these types of households are included in the analysis, as comparisons across them are of interest, both in the study of the allocation of time and in the study of satisfaction with time use. Single households and couple families without children can be viewed as providing a benchmark against which the outcomes of other types of households can be compared. Comparison of lone parents and singles, for example, offer an indication of the impact of children on time allocations and levels of satisfaction with time allocations. Comparisons of those in families with and without children also provide an indication of the effect of children on the outcomes under consideration. Comparison of lone parents and couple families with children can inform on the effects of a change in status from partnered to lone parent on time allocations and levels of satisfaction with time allocations (comparison of singles and lone parents can offer similar information). Both partnered status and the presence of children are important influences on the outcomes analysed in this paper, and both can be examined with a sample having broad coverage.

\section{Measurement of time use}

The time allocation data in the TUS were collected by the diary method. The diary was designed to obtain information on the nature, timing and duration of the respondent's activities for two consecutive specified days. The diary recorded the details of respondents' activities by showing hours with fixed intervals of five minutes, covering 24 hours. All the responses were subsequently coded into a large number of categories. The major categories were personal care activities, 
employment-related activities, education activities, domestic activities, child care activities, purchasing activities, voluntary work and care activities, social and community interaction, and recreation and leisure.

An additional feature of the diary that is useful for many analyses is the distinction between the main activity and the secondary activity. This and related distinctions can be made because the time diary that respondents were required to complete solicited information on both the main and secondary activities, via five questions, 'What is your main activity', 'Who did you do this for', 'What else were you doing at the same time', 'Where were you?' and 'Who was with you at home, or with you away from home'. The availability of information on secondary activities may be important in a study of parental activities, as parents may have to simultaneously multi-task to cover the demands placed on their limited time. ${ }^{3,4}$

The 2006 Time Use Survey also enables the concept of 'time stress' to be explored. Thus, questions in the diary not only recorded people's perception of their time allocations but also their satisfaction with the way they spend their time. This information was self-reported, and the data reviewed below are from the question: 'In general, how satisfied or dissatisfied are you with the way you spent your time over the last two days'.

\section{Descriptive analyses}

In this section, we first present an overview of the way the various family types allocate their time to primary and secondary activities. Following this, the extent of satisfaction with the current pattern of spending time is examined. As the overwhelming majority of lone parents are women, the analyses that follow are limited to women. ${ }^{5}$ Moreover, to limit the effect of study and retirement decisions on the time allocations and levels of satisfaction examined, the analyses are limited to women aged 20-64 years.

\section{Primary time}

Table 1 provides information on the primary time allocated to the major groups of activities for lone mothers, partnered mothers, women in couple families without children, and single women. The top panel of this table covers the working week of Monday through to Friday, while the bottom panel is for the weekend. The times allocated to the various groups of activities are reported to the nearest minute. They are the average minutes per day for each particular primary activity; hence the allocations sum to 1440 minutes, or 24 hours.

It is apparent from the top panel of Table 1 that, on average, lone mothers allocate approximately the same amount of primary time per day to personal care as partnered mothers (averages of 624 minutes and 611 minutes, respectively). In comparison, women in couple families without children and single women spend more primary time in personal care (averages of 655 minutes and 670 minutes, respectively). A similar pattern across household types is observed when leisure is considered. 
Table 1: Time allocation (primary) in minutes per day of women by household type

\begin{tabular}{|c|c|c|c|c|}
\hline \multirow[b]{2}{*}{ Time use } & \multicolumn{4}{|c|}{ Household type } \\
\hline & $\begin{array}{l}\text { Lone } \\
\text { mothers }\end{array}$ & $\begin{array}{c}\text { Partnered } \\
\text { mothers }\end{array}$ & $\begin{array}{c}\text { Women in } \\
\text { childless couples }\end{array}$ & $\begin{array}{l}\text { Single } \\
\text { women }\end{array}$ \\
\hline \multicolumn{5}{|c|}{ (a) Working week } \\
\hline Personal care & 624 & 611 & 655 & 670 \\
\hline Employment & 231 & 198 & 242 & 278 \\
\hline Home duties & 224 & 265 & 227 & 163 \\
\hline Leisure & 220 & 193 & 262 & 275 \\
\hline Child care & 108 & 144 & - & - \\
\hline Other & 33 & 29 & 54 & 54 \\
\hline Total & 1440 & 1440 & 1440 & 1440 \\
\hline Sample size ${ }^{a}$ & 257 & 1320 & 761 & 286 \\
\hline \multicolumn{5}{|l|}{ (b) Weekend } \\
\hline Personal care & 687 & 688 & 714 & 691 \\
\hline Employment & 52 & 39 & 55 & 77 \\
\hline Home duties & 265 & 288 & 265 & 219 \\
\hline Leisure & 298 & 275 & 357 & 397 \\
\hline Child care & 107 & 125 & - & - \\
\hline Other & 31 & 25 & 49 & 56 \\
\hline Total & 1440 & 1440 & 1440 & 1440 \\
\hline Sample size ${ }^{a}$ & 199 & 1025 & 656 & 222 \\
\hline
\end{tabular}

a. Sample size refers to unweighted number of observations.

Larger differences between the ways that lone mothers and partnered mothers allocate time are observed when the focus is on either child care, employment-related activities or home duties. Lone mothers typically allocate less primary time to child care (108 minutes) than partnered mothers (144 minutes). Lone mothers typically also allocate less time than partnered mothers to home duties (224 minutes compared to 265 minutes), about the same amount of time to home duties as women in couple families without children, and much more time than single women allocate to this activity. These patterns are likely to be attributable to the extra home duties associated with children (lone mothers compared to single women), and the specialisation in time use activities within couple families (partnered mothers versus lone mothers).

The flip side of the smaller allocation of time to home duties by lone mothers compared with partnered mothers appears to be in the greater amount of time lone mothers allocate to employment-related activities. Lone mothers allocate, on average, 231 minutes per day to employment-related activities during the working week, which is around one-half an hour more than partnered mothers. Single women allocate the most time, an average of about 278 minutes, to employment-related activities, compared to the other three groups.

The lower panel of Table 1 presents information on the allocation of time to the major categories of activities over Saturday and Sunday. Several observations can be made from a comparison of the data for weekdays and the weekend. During weekends, the time allocated to employment falls dramatically, which allows additional time to be set aside for personal care, home duties and leisure by 
each family type. Interestingly, the time allocated to child care by lone mothers does not change, whereas the time allocated to child care by partnered mothers actually falls. This fall is presumably a reflection of the additional child care undertaken by the spouse during the weekend, compared with the working week.

\section{Secondary time}

As noted above, time allocated to child care as a primary activity does not provide a complete picture of the overall time commitment of parents, as much of the child care is provided as a secondary activity. This may be especially true in the case of lone mothers. Hence, analysis of secondary time allocations is of interest.

Note that, in contrast to primary activities where the time allocations sum to 24 hours, the times allocated to secondary activities do not sum to 24 hours, as for the greater part of the day individuals engage in only one (primary) activity. The typical woman in fact provides information on how they allocated only between five to eight hours of each day to secondary activities. The only time use categories with meaningful time allocations are leisure and child care. Hence, the presentation in this discussion adopts a simple three-fold categorisation of leisure, child care and other.

Table 2 lists information on the time use in secondary activities during weekdays (top panel) and at weekends (bottom panel). Lone mothers spend, on average, three and one-third hours each weekday looking after children while doing other primary activities. This time allocation is 45 minutes less than the approximately four hours allocated by partnered mothers. This smaller time allocation for lone mothers compared with partnered mothers may have its origins in the findings reported by Zick and Bryant (1996). ${ }^{6}$ They found that when parents' work hours increased, both the primary and secondary child care times decreased. Hence, as the earlier discussion showed that lone mothers allocate more time to employment-related activities than partnered mothers, the prior evidence suggests that they will allocate less time to child care. Of course, there may be other factors at work here, such as the age of children. This possibility will be investigated in the multivariate analysis below.

Lone mothers allocate slightly under three and one-half hours, on average, per weekday to leisure as a secondary activity, whereas partnered mothers allocate a little over three and two-thirds hours (the differential in time allocated is 16 minutes). The time allocated to leisure as a secondary activity by women with children is at least half an hour less than that allocated by women in other types of households. Presumably, this is, in large part, a knock-on effect of the time needed for child care.

The pattern of time allocations over the weekend mirrors that during the weekdays, even though there is more time, in total, set aside for the secondary activities during the weekend. Hence, lone mothers allocate 30 minutes less per day, on average, over the weekend to secondary child care activities than partnered mothers. They also allocate almost 20 minutes less per day to leisure activities than partnered mothers. Both lone mothers and partnered mothers 
allocate less time to secondary leisure pursuits over the weekend, compared to women in the other types of households, where the leisure time activities account for over four and one-half hours per day.

Table 2: Time allocation (secondary) in minutes per day of women by household type

\begin{tabular}{lcccc}
\hline & \multicolumn{4}{c}{ Household type } \\
\hline Time use & $\begin{array}{c}\text { Lone } \\
\text { mothers }\end{array}$ & $\begin{array}{c}\text { Partnered } \\
\text { mothers }\end{array}$ & $\begin{array}{c}\text { Women in } \\
\text { childless couples }\end{array}$ & $\begin{array}{c}\text { Single } \\
\text { women }\end{array}$ \\
\hline (a) Working week & 207 & & 256 & 251 \\
Leisure & 201 & 223 & - & - \\
Child care & 36 & 245 & 43 & 28 \\
Other & 444 & 34 & 299 & 279 \\
\hline Total & 502 & & \\
\hline
\end{tabular}

\begin{tabular}{lcccc}
\hline (b) Weekend & & & & \\
Leisure & 237 & 253 & 286 & 287 \\
Child care & 211 & 241 & - & - \\
Other & 35 & 37 & 40 & 51 \\
\hline Total & 483 & 531 & 326 & 338 \\
\hline
\end{tabular}

a. See Table 1 for sample sizes.

\section{Satisfaction with current time allocation}

Table 3 presents information on the satisfaction of women in each of the four household types considered here with their current time allocations. The table contains information on the distribution across the satisfaction categories for each household type, and the mean level of satisfaction that is obtain by treating the satisfaction score as a cardinal variable that ranges from 1 (very dissatisfied) to 5 (very satisfied). The first thing to note about the Table 3 data is that very few women report being dissatisfied with the way they currently allocate their time. The highest percentage representation in the combined 'dissatisfied' and 'very dissatisfied' categories is the approximately six per cent for lone parents. The lowest is the two per cent for singles. As such, the differences across household types in the negative self-reports on satisfaction with time use are not meaningful, and so the discussion concentrates on the three remaining satisfaction categories.

Table 3: Satisfaction with current pattern of spending time (percentage) and mean score ${ }^{a}$

\begin{tabular}{lccccccc}
\hline Household type & Very satisfied & Satisfied & $\begin{array}{c}\text { Both satisfied } \\
\text { and dissatisfied }\end{array}$ & Dissatisfied & $\begin{array}{c}\text { Very } \\
\text { dissatisfied }\end{array}$ & Total & Mean score \\
\hline Lone mothers & 10.7 & 47.0 & 35.9 & 3.8 & 2.6 & 100 & 3.59 \\
Partnered mothers & 15.4 & 51.2 & 29.0 & 2.8 & 1.6 & 100 & 3.76 \\
Women in & 22.0 & 51.5 & 21.1 & 3.3 & 2.1 & 100 & 3.88 \\
childless couples & 24.6 & 44.4 & 28.9 & 1.1 & 1.0 & 100 & 3.90 \\
Single women & & & & & & & \\
\hline
\end{tabular}

a. Mean computed by assigning a value of 1 to 'very dissatisfied', 2 to 'dissatisfied', 3 to 'both satisfied and dissatisfied', 4 to 'satisfied' and 5 to 'very satisfied'. 
The Table 3 data show that 11 per cent of lone mothers are very satisfied with their current pattern of time allocation, compared to 25 per cent of single women, and 22 per cent of women in couple families with no resident children. Partnered mothers similarly register a low degree of 'Very satisfied' 15 per cent. At face value, this suggests that the mere presence of children may have a major impact on how satisfied women feel with the way they (are able to) use their time.

The low representation in the 'Very satisfied' category in relation to satisfaction with their current time allocation for lone mothers is associated with a relatively high representation in the 'Both satisfied and dissatisfied' category. In comparison, the low representation in the 'Very satisfied' category among partnered mothers is largely linked to a relatively high representation in the 'Satisfied' category.

A useful summary of these satisfaction data is provided by the mean scores listed in the final column. These show that the mean satisfaction score for lone mothers, at 3.59, is less than those of partnered mothers (mean score of 3.76), women in childless couples (3.88) and single women (3.90). Thus, the comparisons between lone mothers and the other household types provide evidence on the potential adverse implications for satisfaction with time allocation of both the presence of a child and the task overload that lone mothers appear to face as they juggle family and other responsibilities.

\section{Statistical analyses}

The data presented in Tables 1, 2 and 3 illustrate differences between lone mothers and women in other types of households in terms of primary and secondary time allocations, and in the level of satisfaction with the allocation of time. These differences could be associated with simply being a lone mother. However, they could also arise because of differences in the characteristics of the groups examined. For example, lone parents were shown by Birch and colleagues (2009) to have lower educational attainments than members of other household types, and to be more likely to reside in low-socioeconomic status neighbourhoods. Both factors could affect the way individuals allocate their time and how satisfied they are with their time allocation. Hence, it is important to take account of differences in the background characteristics of the women in the different household types. This can be achieved using multivariate analysis. The multivariate analysis undertaken below provides an assessment of the influence of a particular characteristic (for example, being a lone mother) on time allocations or satisfaction levels after account is taken of the effect of other potential influences on these outcomes, such as educational attainment, age and region of residence. In other words, it enables 'other things being equal' effects to be quantified.

Various multivariate approaches could be applied. Here, the factors that influence the time allocations of women in the various types of households are examined using Ordinary Least Squares (OLS). This approach appears 
to offer an adequate description of the data (Le \& Miller 2010, 2012). The framework adopted is to estimate separate time allocation equations for each of the major time use categories used in Table 1, namely: (i) personal care; (ii) employment-related activities; (iii) home duties; (iv) child care; (v) leisure; and (vi) other, although the results for the final, residual set of activities are not reported. The estimated OLS coefficients for each variable (for example, lone mothers) have the appealing property that they sum to zero across these six major time use categories. In other words, they show how time is reallocated across these time use categories when there is a change in an explanatory variable. In each instance the allocation of time to the particular activity is related to: variables for age (a quadratic specification), educational attainment (five dichotomous variables), self-reported health status (three dichotomous variables), English proficiency (two dichotomous variables), the socioeconomic status of the area of residence ${ }^{7}$ (three dichotomous variables), home ownership (one dichotomous variable), and children and the availability of child care (four dichotomous variables for couple families with children and lone parents). These explanatory variables are typical of those used in studies of the determinants of time allocations, and are generally argued to reflect either the individual's preferences for time use, or the constraints that they face when making time allocations (Le \& Miller 2012). ${ }^{8}$ Differences across the four household types are captured by intercept shifts. ${ }^{9}$ There are various limitations of this approach, such as the potential for variables that are unobserved by the researcher to affect each time allocations and, along with the linkages across time uses associated with a 24-hour per day time constraint, result in a correlation across the residuals in the estimated models. These limitations could be accommodated with appropriate modifications of the econometric approach. OLS estimation, however, yields findings similar to the more general approaches (see Le \& Miller 2012), and for this reason is used in the current study. ${ }^{10}$

The set of explanatory variables outlined for inclusion in the time allocation models is also used in the study of the satisfaction with time use. Both OLS and an ordered probability (probit) model are employed as methods of estimation in this latter set of analyses. The application of OLS to the satisfaction data treats the satisfaction scale as cardinal. In contrast, when the ordered probability model is applied, the satisfactions scale is treated as an ordinal measure (Kristofferson 2010; Le \& Miller 2013). The literature suggests that the difference in assumptions behind the statistical approaches does not affect the results (Ferrer-i-Carbonell \& Frijters 2004). Results from both the OLS and Ordered Probit models will be reported, following the advice of Kristofferson (2010: 104) that 'A welcome trend has developed for reporting on both models imposing cardinality and those which do not, essentially covering both possibilities'. 
Table 4: Estimates of determinants of primary time allocations

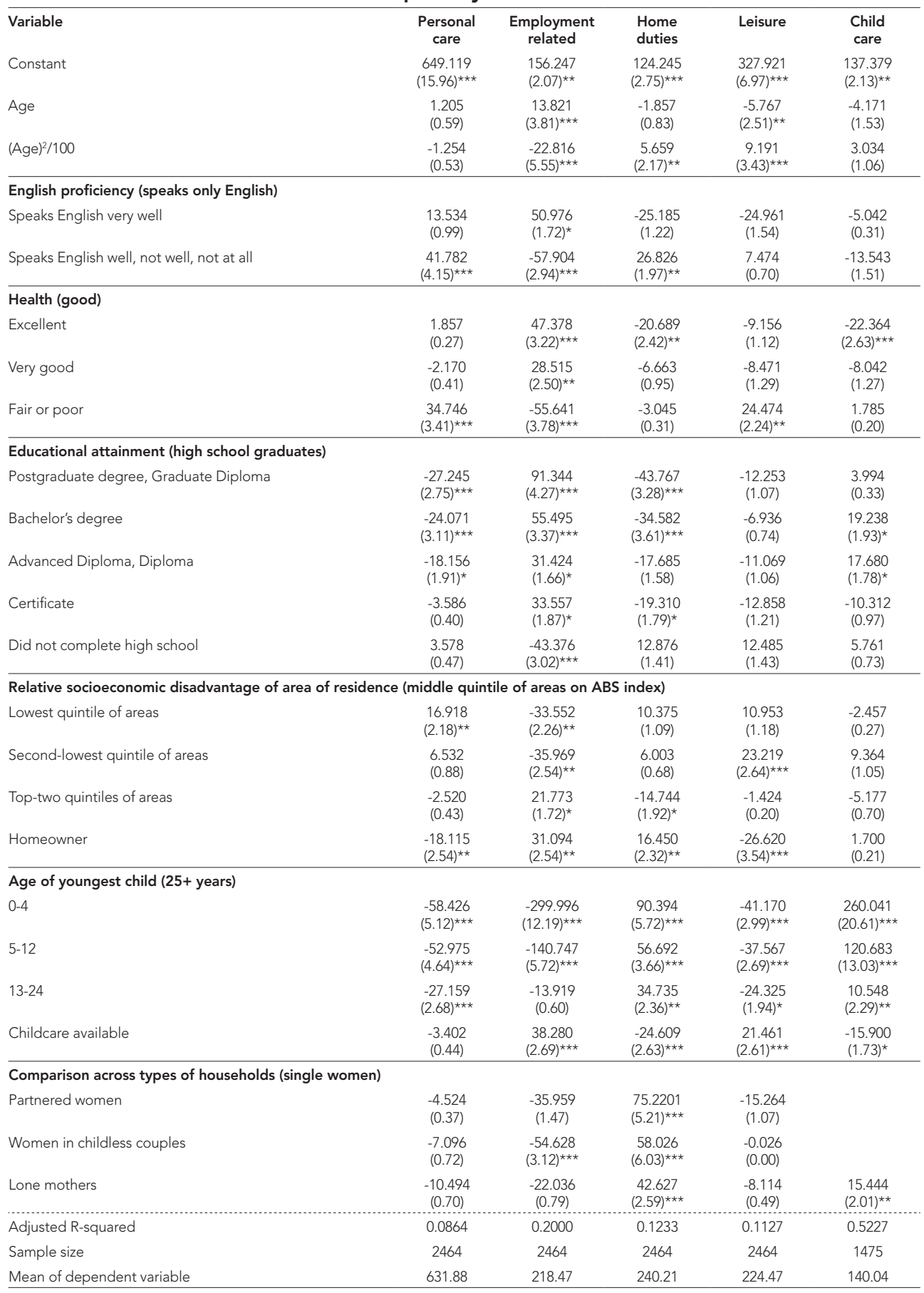

Notes: Absolute value of heteroscedasticity-consistent ' $t$ ' statistics in parentheses; ${ }^{* *}=$ significant at the 1 percent level; ${ }^{* *}=$ significant at the 5 percent level; * = significant at the 10 percent level. 


\section{Primary time allocations}

Table 4 lists the estimates of the determinants of the allocation of time to primary activities. The adjusted R-squared in these equations, which range from 0.09 (personal care) to 0.52 (child care), are similar in value to the goodness of fit achieved in comparable studies, and the estimated coefficients conform to findings established in prior research. In most cases the results are best read from the perspective of determining the effect of a particular variable on either employment-related activities or child care (which appear to be the time use activities that individuals, in practice, have most discretion over), and then tracing through the effect of that variable on the other activities to see how the changed allocation of time to the first two activities is accommodated.

For example, women with a child aged 0-4 years allocate 260 minutes more to child care than women with only dependent children. This extra time allocation to child care is associated with an extra 90 minutes being set aside for home duties, but with 58 fewer minutes for personal care, 300 fewer minutes for employment-related activities, and 41 fewer minutes for leisure activities. These shifts in the allocation of time, as well as those associated with the other personal characteristics in Table 4, are intuitively reasonable. Discussion will now focus on the effects of the type of household on the way women allocate their time.

Once the effects of the personal characteristics and area of residence are taken into account, there are only minor differences across the four household types in the allocation of time to the five time use categories listed in Table 4. Specifically, there are no statistically significant differences between lone mothers, women in families where there are no resident children or partnered mothers compared to single women in the time allocated to either personal care or leisure. Partnered mothers, women in families where there are no children present and lone mothers allocate significantly more time to home duties than the single women benchmark group: 75 minutes more and 58 minutes more, respectively, for the two types of couple families, and 43 minutes more for lone mothers. The additional time that lone mothers allocate to home duties compared to single women is presumably linked to the presence of non-dependent children in the household (the benchmark group). The greater time allocated to home duties by women in couple families without children will be associated with the specialisation in activities in that family type traditionally the husband in employment-related activities and the wife in home duties. The extra time that women in couple families with children allocate to home duties compared to single women will reflect both of the factors behind the time allocations to home duties of lone mothers and women in couple families without children. The fact that the coefficient for couple families with children is less than the sum of the coefficients for the other two household types can be argued to reflect economies of scale in home duties.

The time allocated to employment-related activities is lower for partnered mothers, women in couple families without children and for lone mothers than it is for single women, but the difference is only statistically significant in the case of women in couple families without children. There are no statistically 
significant differences between any two of the three coefficients for household type in this model for employment-related activities. The fact that there is a significantly lower allocation of time to employment-related activities for women in couple families without children than for single women, but not for women in couple families with children, is interesting. Given that the estimating equation controls for the presence of dependent children, this finding seems to imply that women in couple families with older children return to work to help meet family budget commitments.

Finally, lone mothers allocate more time to child care than partnered mothers, ceteris paribus. Given the specification of the model, this lone mother shift factor implies that lone mothers allocate more time to child care for each of the categories of children variables. This is likely to be associated with the care that the husband provides in couple families that substitutes for care provided by the wife.

The main comparison to be drawn from Table 4 is between lone mothers and partnered mothers. Lone mothers allocate a little more time to employment-related activities (14 minutes), more time to leisure ( 7 minutes), 15 minutes more to child care, but less time to personal care (6 minutes) and 32 minutes less to home duties. These are reasonably small variations, and they are not, individually, statistically significant. Hence, despite what appears to be very different personal circumstances, lone mothers have an allocation of time that is remarkably similar to that of partnered mothers (Craig 2005; Craig \& Mullan 2012). One interpretation of this is that particular personal circumstances (for example, the presence of a young child) dictate a certain allocation of time, and divergences from this are difficult (Kendig \& Bianchi 2008). Nevertheless, the departures observed are in the expected direction (for example, lone mothers allocating relatively more time to employment-related activities), and could sow the seeds for the task overload tensions often discussed in the literature, and hence be revealed in lower levels of satisfaction with time allocations. Before investigating this, however, the determinants of the allocation of time to secondary activities are examined.

\section{Secondary time allocations}

Table 5 lists selected estimates of the determinants of the allocation of time to secondary activities. As discussed above, only two activities have sizeable amounts of time allocated to them while the individuals are engaged in other, primary activities, namely leisure and child care. Here we list and discuss only the partial effects of the variables for the presence of children and household type on these activities.

The main circumstance that influences the time allocated to secondary activities is the presence of children under the age of 12 years. Children in this age bracket are associated with up to one-hour less of leisure time per day as a secondary activity, and over six and one-half hours of additional time allocated 
to child care per day. As they are also associated with significant shifts in the way primary time is allocated, the Table 5 findings reinforce the notion that young children are (mother) time intensive.

Table 5: Selected estimates of determinants of secondary time allocations

\begin{tabular}{|c|c|c|}
\hline Variable & Leisure & Child care \\
\hline \multicolumn{3}{|l|}{ Age of youngest child ( $25+$ years) } \\
\hline $0-4$ & $\begin{array}{l}-61.489 \\
(3.15)^{\star \star \star}\end{array}$ & $\begin{array}{c}393.155 \\
(11.92)^{\star \star \star}\end{array}$ \\
\hline $5-12$ & $\begin{array}{l}-50.320 \\
(2.65)^{\star \star \star}\end{array}$ & $\begin{array}{c}183.463 \\
(7.11)^{\star \star \star}\end{array}$ \\
\hline $13-24$ & $\begin{array}{l}-0.216 \\
(0.01)\end{array}$ & $\begin{array}{l}7.369 \\
(0.69) \\
\end{array}$ \\
\hline \multicolumn{3}{|c|}{ Comparison across types of households (single women) } \\
\hline Partnered women & $\begin{array}{c}12.541 \\
(0.65)\end{array}$ & \\
\hline Women in childless couples & $\begin{array}{c}13.840 \\
(0.98)\end{array}$ & \\
\hline Lone mothers & $\begin{array}{c}-3.773 \\
(0.18)\end{array}$ & $\begin{array}{l}35.788 \\
(1.72)^{\star}\end{array}$ \\
\hline Adjusted R-squared & 0.0261 & 0.3215 \\
\hline Sample size & 2464 & 1475 \\
\hline Mean of dependent variable & 235.02 & 244.08 \\
\hline
\end{tabular}

Notes: Absolute value of heteroscedasticity-consistent ' $t$ ' statistics in parentheses; estimating equations contain the same set of explanatory variables as listed in Table $4 ;{ }^{* \star *}=$ significant at the 1 percent level; ${ }^{*}=$ significant at the 10 percent level.

Finally, it is apparent that the time allocated to leisure as a secondary activity does not vary across the four household types. The time that lone mothers allocate to child care as a secondary activity is, however, 36 minutes greater than that allocated by partnered mothers, all other factors the same. This effect is statistically significant at the 10 per cent level, and presumably has its origins in the lone mother usually being the sole care provider in the household and hence being on call at all hours (compared with couple families where time allocated by the father can substitute for care provided by the mother).

\section{Satisfaction with current allocation of time}

The responses to the question on satisfaction with the current allocation of time are examined using the covariates employed in the analyses of the allocation of time to primary and secondary activities. As well, information on the time allocated to primary and secondary activities is included in several of the models estimated. ${ }^{11}$ There is, however, one departure from the approach to modelling used above: in the first instance, we present estimates from a model that omits the variables for the presence and ages of children - this omission offers a powerful means of demonstrating the impact that children have on the relative levels of satisfaction with the allocation of time across the household types examined in this study.

The dependent variable for these analyses has been formed from the categorical responses 'very dissatisfied', 'dissatisfied', 'both satisfied and dissatisfied', 'satisfied' and 'very satisfied'. For the estimations using OLS the dependent 
variable is a cardinal variable that is obtained by assigned scores to these categories that range from 1 (very dissatisfied) to 5 (very satisfied). Hence higher values of this satisfaction score represent higher levels of satisfaction. For the estimations using the Ordered Probit method, the same ordering of 1 (very dissatisfied) to 5 (very satisfied) is used, though in this case it is only the ranking that is important, as the score is treated as an ordinal measure.

The findings from the equations estimated by OLS (see column (i) of Table 6) and those using the Ordered Probit model (see columns (ii)-(v) of Table 6) are very similar (Ferrer-i-Carbonell \& Frijters 2004; Le \& Miller 2013). For space reasons, we present parallel sets of estimates from the two methods of estimation only for the first model (where the variables for the presence and ages of children, together with the related variable for the availability of child care, are omitted). For the remaining three models, namely the equation that includes the 'children' variables, the equation that also has variables for the allocation of time to primary activities, and the equation that has variables for the allocation of time to secondary activities, we present only the estimates from the Ordered Probit model. ${ }^{12}$

Table 6 contains the estimates of the determinants of the level of satisfaction with the current allocation of time. According to the estimates in the first two columns, there are five sets of factors that affect how satisfied individuals are with the way they allocate their time. The first of these is age, and the data are characterised by the conventional U-shaped relationship between age and levels of satisfaction (Blanchflower \& Oswald 2008). In other words, just as the general levels of well-being studied in previous research are found to be relatively low for those around 30 years of age, the levels of satisfaction with time allocations are also relatively low at this time in life. Thus, the life-cycle effects on satisfaction levels appear to be pervasive across types of satisfaction data.

The second set of influences on satisfaction with the current allocation of time is the self-reported health status - individuals who report their health as excellent are much more satisfied with the way they have allocated their time than individuals who report their health as poor. Good health may allow a woman to achieve her desired time allocation, with those in poor health facing constraints in this regard. However, similar findings emerge in the estimating equations that take account of the amount of time actually allocated to various activities, suggesting there is a direct link between health status and the levels of satisfaction with the current allocation of time.

Third, the area in which the individual resides appears to affect how satisfied they are with the way time has been allocated. Specifically, individuals living in higher status neighbourhoods are slightly less satisfied with the way they have allocated their time than residents of other neighbourhoods. The main way such an effect might emerge in the data is through the comparisons individuals make, with comparisons being made about time allocations with those in the local area of residence. 
Fourth, home owners are shown to have higher levels of satisfaction with the current allocation of time. Home ownership is shown in Table 4 to exercise a major impact on the allocation of primary time - towards employment-related activities and home duties and away from leisure and personal care. The Table 6 evidence suggests that these changes leave home owners feeling better in terms of the times allocated to specific tasks. Home ownership is also an indicator of wealth, although the data set does not contain information on equity that would enable the links between wealth and satisfaction with time allocations to be quantified.

Table 6: Estimates of determinants of satisfaction with time allocation

\begin{tabular}{|c|c|c|c|c|c|}
\hline \multirow[b]{2}{*}{ Variable } & \multirow{2}{*}{$\begin{array}{c}\text { OLS } \\
\text { (i) }\end{array}$} & \multicolumn{4}{|c|}{ Ordered Probit } \\
\hline & & (ii) & (iii) & (iv) & (v) \\
\hline Constant & $\begin{array}{c}4.167 \\
(15.42)^{\star \star \star}\end{array}$ & $\begin{array}{c}2.696 \\
(7.48)^{\star \star \star}\end{array}$ & $\begin{array}{c}2.308 \\
(6.13)^{\star \star \star}\end{array}$ & $\begin{array}{c}2.327 \\
(5.91)^{\star \star \star}\end{array}$ & $\begin{array}{c}2.324 \\
(6.14)^{\star \star \star}\end{array}$ \\
\hline Age & $\begin{array}{c}-0.030 \\
(2.17)^{\star \star}\end{array}$ & $\begin{array}{c}-0.041 \\
(2.34)^{\star \star}\end{array}$ & $\begin{array}{l}-0.020 \\
(1.08)\end{array}$ & $\begin{array}{l}-0.016 \\
(0.86)\end{array}$ & $\begin{array}{l}-0.020 \\
(1.10)\end{array}$ \\
\hline \multicolumn{6}{|l|}{ English proficiency (speaks only English) } \\
\hline Speaks English very well & $\begin{array}{l}0.037 \\
(0.34)\end{array}$ & $\begin{array}{l}0.030 \\
(0.91)\end{array}$ & $\begin{array}{l}0.061 \\
(0.38)\end{array}$ & $\begin{array}{l}0.072 \\
(0.45)\end{array}$ & $\begin{array}{l}0.053 \\
(0.33)\end{array}$ \\
\hline Speaks English well, not well, not at all & $\begin{array}{c}-0.090 \\
(1.04)\end{array}$ & $\begin{array}{c}-0.116 \\
(1.08)\end{array}$ & $\begin{array}{l}-0.067 \\
(0.62)\end{array}$ & $\begin{array}{c}-0.072 \\
(0.66)\end{array}$ & $\begin{array}{l}-0.082 \\
(0.75)\end{array}$ \\
\hline Very good & $\begin{array}{c}0.093 \\
(2.35)^{\star \star}\end{array}$ & $\begin{array}{c}0.134 \\
(2.45)^{\star \star}\end{array}$ & $\begin{array}{c}0.136 \\
(2.46)^{\star \star}\end{array}$ & $\begin{array}{c}0.143 \\
(2.59)^{\star \star \star}\end{array}$ & $\begin{array}{c}0.136 \\
(2.46)^{\star \star}\end{array}$ \\
\hline Fair or poor & $\begin{array}{c}-0.326 \\
(4.96)^{\star \star \star}\end{array}$ & $\begin{array}{c}-0.405 \\
(5.12)^{\star \star \star}\end{array}$ & $\begin{array}{c}-0.395 \\
(5.00)^{\star \star \star}\end{array}$ & $\begin{array}{c}-0.413 \\
(5.18)^{\star \star \star}\end{array}$ & $\begin{array}{c}-0.395 \\
(4.99)^{\star \star \star}\end{array}$ \\
\hline \multicolumn{6}{|c|}{ Educational attainment (high school graduates) } \\
\hline Postgraduate degree, Graduate Diploma & $\begin{array}{c}-0.005 \\
(0.07)\end{array}$ & $\begin{array}{c}-0.022 \\
(0.22)\end{array}$ & $\begin{array}{l}-0.019 \\
(0.19)\end{array}$ & $\begin{array}{l}-0.003 \\
(0.03)\end{array}$ & $\begin{array}{l}-0.011 \\
(0.11)\end{array}$ \\
\hline Bachelor's degree & $\begin{array}{l}-0.014 \\
(0.24)\end{array}$ & $\begin{array}{l}-0.022 \\
(0.29)\end{array}$ & $\begin{array}{l}-0.040 \\
(0.52)\end{array}$ & $\begin{array}{c}-0.036 \\
(0.46)\end{array}$ & $\begin{array}{l}-0.036 \\
(0.46)\end{array}$ \\
\hline Advanced Diploma, Diploma & $\begin{array}{l}0.018 \\
(0.27)\end{array}$ & $\begin{array}{l}0.005 \\
(0.53)\end{array}$ & $\begin{array}{l}-0.013 \\
(0.14)\end{array}$ & $\begin{array}{l}-0.012 \\
(0.13)\end{array}$ & $\begin{array}{l}-0.006 \\
(0.07)\end{array}$ \\
\hline Lowest quintile of areas & $\begin{array}{l}0.049 \\
(0.93)\end{array}$ & $\begin{array}{l}0.068 \\
(0.90)\end{array}$ & $\begin{array}{l}0.088 \\
(1.17)\end{array}$ & $\begin{array}{l}0.082 \\
(1.08)\end{array}$ & $\begin{array}{l}0.084 \\
(1.11)\end{array}$ \\
\hline Second-lowest quintile of areas & $\begin{array}{l}-0.019 \\
(0.39)\end{array}$ & $\begin{array}{l}-0.031 \\
(0.43)\end{array}$ & $\begin{array}{l}-0.039 \\
(0.55)\end{array}$ & $\begin{array}{l}-0.053 \\
(0.74)\end{array}$ & $\begin{array}{l}-0.039 \\
(0.54)\end{array}$ \\
\hline Top-two quintiles of areas & $\begin{array}{c}-0.131 \\
(3.01)^{\star \star \star}\end{array}$ & $\begin{array}{c}-0.167 \\
(2.78)^{\star \star \star}\end{array}$ & $\begin{array}{c}-0.170 \\
(2.82)^{\star \star \star}\end{array}$ & $\begin{array}{c}-0.167 \\
(2.77)^{\star \star \star}\end{array}$ & $\begin{array}{c}-0.168 \\
(2.78)^{\star \star \star}\end{array}$ \\
\hline Homeowner & $\begin{array}{c}0.143 \\
(3.09)^{\star \star \star}\end{array}$ & $\begin{array}{c}0.170 \\
(2.83)^{\star \star \star}\end{array}$ & $\begin{array}{c}0.165 \\
(2.75)^{\star \star \star}\end{array}$ & $\begin{array}{c}0.178 \\
(2.94)^{\star \star \star}\end{array}$ & $\begin{array}{c}0.166 \\
(2.75)^{\star \star \star}\end{array}$ \\
\hline
\end{tabular}




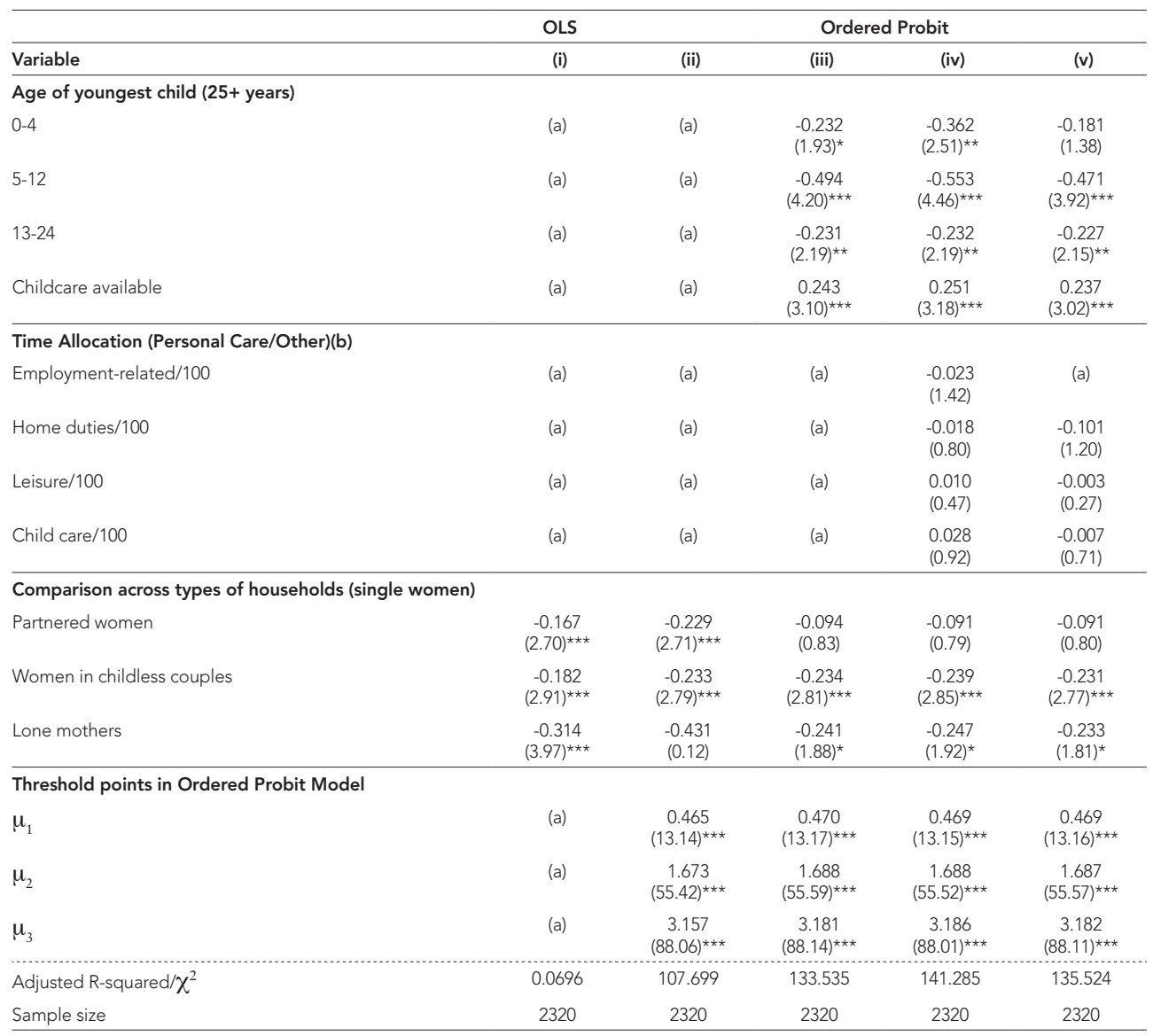

Notes: Absolute value of ' $t$ ' statistics in parentheses; (a) = variable not entered; $(b)=$ refers to primary time allocation in column (iv) and secondary time allocation in column $(\mathrm{v}){ }^{* \star \star}=$ significant at the 1 percent level; ${ }^{\star \star}=$ significant at the 5 percent level; ${ }^{*}=$ significant at the 10 percent level.

Fifth, there are statistically significant variations in the level of satisfaction with the current allocation of time across the four types of households distinguished in the analysis. Compared to the single women benchmark group, women in couple families without children ( 0.18 of a point), partnered mothers $(0.17$ of a point) and lone mothers ( 0.31 of a point on the five-point satisfaction scale) have lower levels of satisfaction with their current allocations of time. The constraints, compromises and responsibilities of family life therefore seem to have an impact on the way women can allocate their time that has an adverse effect on their level of satisfaction. The 0.31 point difference between single women and lone mothers is almost identical to the difference in mean levels of satisfaction presented in Table 3. This indicates that control for the other determinants of satisfaction with time allocations does not alter the difference in satisfaction levels between these groups. The statistical control for the other determinants of satisfaction with time allocations does affect the other comparisons across household types, particularly that involving women in childless couples, where the multivariate analysis indicates a much smaller 
difference $(0.18$ point $)$ between women in childless couples and single women than the 0.29 point difference for this comparison in the unadjusted means of Table 3.

The model of column (iii) contains all the variables that formed the basis of the study of the allocation of time to primary and secondary activities in the previous two sub-sections (that is, the estimating equation includes variables for the presence and ages of children, and for the availability of child care). The 'children' variables are statistically significant as a group, and each is individually significant at the six per cent level of significance or better. Children are associated with lower levels of satisfaction with the current allocation of time. The effect of the age of the youngest child is greatest where the child is 5-12 years of age. This is an age group where the children are less mother-time intensive and more market goods-intensive, which may necessitate greater involvement in paid work (see Table 4). This switch in time allocations between child care and employment-related activities at a time when children are relatively young may be why there is this negative impact on the level of satisfaction with the current time allocation, although longitudinal data will be needed to pursue this speculation further. The availability of child care is associated with higher levels of satisfaction with the current allocation of time. Being able to access child care would relax constraints on time allocations, and hence be associated with the higher levels of satisfaction observed in these results.

The inclusion of the 'children' variables in the model is associated with two major changes to the estimated effects of the other variables. First, the age variables, which were associated with a pronounced U-shaped effect in the first specification, are no longer statistically significant. In other words, the lower levels of satisfaction among the 'middle' aged women compared to both younger and older women in the first estimation was in fact a 'children' effect.

Second, while women in couple families without children remain associated with lower levels of satisfaction with their time allocation compared to singles of approximately the same magnitude as before, the estimated effects associated with partnered mothers and lone mothers are now much smaller, with the effect for partnered mothers no longer statistically significant while the lone mothers effect is marginally significant $(\mathrm{p}=0.06)$. Nevertheless, being a lone mother is associated with lower levels of self-reported satisfaction with the current allocation of time. Table 7 lists marginal effects calculated from the Ordered Probit model which illustrate this. These marginal effects are the, all other things being equal, shifts in the distribution across the satisfaction categories of partnered mothers, women in couple families without children, and lone mothers compared to the single women benchmark category.

The next two models include the variables for the time allocated to primary activities (column (iv)) and to secondary activities (column (v)). It is clear that the times actually allocated to these activities are not major determinants of how satisfied women are with the way they have allocated their time. Thus, it must 
be the personal preferences that confront an actual (required) time allocation that generate the self-reported levels of satisfaction. Importantly, from the perspective of the focus of this study, lone mothers are shown in each model to have a statistically significant lower level of satisfaction with their current allocation of time than the single women benchmark group.

Table 7: Marginal effects (as a percentage) associated with household type, compared with the single women benchmark

\begin{tabular}{lccccc}
\hline & \multicolumn{5}{c}{ Satisfaction category } \\
\hline Household type & $\begin{array}{c}\text { Very } \\
\text { dissatisfied }\end{array}$ & Dissatisfied & Both/neither & Satisfied & $\begin{array}{c}\text { Very } \\
\text { satisfied }\end{array}$ \\
\hline Partnered mothers & 0.36 & 0.53 & 2.46 & -1.09 & -2.25 \\
Women in childless couples & 0.99 & 1.41 & 6.09 & -3.15 & -5.34 \\
Lone mothers & 1.13 & 1.54 & 6.24 & -3.71 & -5.21 \\
\hline
\end{tabular}

Note: Rows may not sum to 0.00 due to rounding.

\section{Concluding comments}

The number of lone parent families has increased considerably in recent decades. Most of these are headed by women. They face three factors that have been identified as leading to job/family role strain in Burden (1986): being a woman, being a mother, and being the sole carer of a child. This paper examines the time allocation of lone mothers to both primary and secondary activities, and the reported level of satisfaction with the current allocation of time. Comparisons are offered with single women, women in couple families without children, and partnered mothers.

There are three main sets of findings. First, there are only fairly minor differences between lone mothers and the other types of households in the way time is allocated across personal care, employment-related activities, home duties, leisure and child care, once account is taken of other characteristics and circumstances that affect time allocations. Foremost amongst these is the presence of young children, who are shown to be associated with marked reductions in employment-related activities, personal care and leisure, and equally marked increases in home duties and child care. This finding holds for both primary time activities and secondary time activities, and the finding is consistent with a growing body of literature. The explanation typically offered is that 'there is a threshold of parental time that must be provided to a child, regardless of whether a parent is absent' (Kalenkoski et al. 2007: 373).

Second, in analyses of the satisfaction with time allocations that do not take account of the presence of children, lone mothers are shown to have the lowest level of satisfaction of the four types of households examined in this study. Single women record the highest level of satisfaction, with couple families (either those with children or those without children) characterised by intermediate levels of satisfaction. Third, once account is taken of the negative effect that children have on the satisfaction with the allocation of time, the ranking of types of households in terms of satisfaction with the current allocation of time 
changes. Partnered mothers report a level of satisfaction that does not differ significantly from that of single women. Lone mothers, together with women in childless couples, have a level of satisfaction that is significantly lower than that of single women.

Hence, lone mothers have lower levels of satisfaction with the current allocation of time due to both the fact that they have young children and due to the fact that they are parenting alone. The tensions associated with time use among lone mothers discussed in the literature are real, and important. Thus, while examination of time allocations to the care of children might indicate that the children of lone parents are adequately catered for in terms of maternal time allocation, the implication of this for the well-being of the lone parents needs to be recognised (Kendig \& Bianchi 2008). In particular, the analyses reported in this paper suggest that the adjustment in the time allocations of lone parents comes at a cost, in the form of their lower satisfaction with the allocation of their time.

The level of utility is generally argued by economists to provide an encompassing measure of well-being that can be used to assess the results of individual decision making and welfare reforms. However, we do not have an acceptable measure of utility. Measures of satisfaction have been proposed as being able to serve the same function. As Dockery (2012: 899) notes, 'Underpinning the happiness literature is the belief that such measures of subjective wellbeing - happiness or life-satisfaction - can be used to make valid inferences about individuals' utility'. From this perspective, the end result of the utility maximising exercise that results in the allocations of time described in Tables 1 and 2 is a situation where lone mothers' time trade-offs are associated with lower well-being, or equivalently, a lower level of welfare. As such, an equity argument can be made for policy that facilitates greater maternal care time among lone parents. This would represent a reversal of the direction of recent welfare-to-work policy changes in Australia. Commencing in the 2005-2006 budget, the Australian Government implemented a number of measures that were aimed at increasing the involvement of lone parents in paid employment and reducing their welfare dependency. These reduced lone parents' entitlements to welfare benefits, and imposed obligations on many to participate in the workforce. Various job search requirements had to be fulfilled to remain eligible for welfare support (Summerfield et al. 2010). Summerfield and colleagues (2010) argued that the reforms were likely to increase the incidence of poverty for many lone parents. They state 'The potentially negative consequences of the reforms arguably arise from a failure of reformers to appreciate the broader social context - that there is not a level playing field between mothers and fathers in the employment market and that we are not yet in a world of meaningful shared care arrangements' (Summerfield et al. 2010: 77). The analyses reported in this paper appear to confirm this uneven playing field, in that lone mothers have lower levels of satisfaction than women in other types of households. The analyses show that satisfaction with time allocation 
data can be studied to reveal how time pressures differ across family types. Collection of satisfaction and related well-being data for parents and children is therefore to be encouraged (Kendig \& Bianchi 2008).

\section{Acknowledgements}

The authors acknowledge financial support from the Australian Research Council DP0770213, helpful comments from the editors and two anonymous referees, and research assistance from Corinne Hooi.

\section{References}

ABS (Australian Bureau of Statistics) (2006a) Time Use Survey: User Guide, Cat. No. 4150.0.

- (2006b) Socio-Economic Indexes for Areas (SEIFA) - Technical Paper 2006, Cat. No. 2039.0.55.001.

- (2007) Australian Social Trends, Cat. No. 4102.0.

- (2011) Labour Force, Australia: Labour Force Status and Other Characteristics of Families, June 2011, Cat. No. 6224.0.55.001.

Baxter, J. \& Western, M. (1998) 'Satisfaction with housework: examining the paradox’, Sociology, 32 (1), 101-20.

Bell, A., Finch, N., Valle, I.L., Sainsbury, R. \& Skinner, C. (2005) A question of balance: lone parents, child care and work, Norwich, Department for Work and Pensions.

Benin, M.H. \& Agostinelli, J. (1988) 'Husbands' and wives' satisfaction with the division of labor', Journal of Marriage and the Family, 50 (2), 349-61.

Birch, E.R., Le, A.T. \& Miller, P.W. (2009) Household Divisions of Labour: Teamwork, Gender and Time, New York, Palgrave Macmillan.

Blanchflower, D.G. \& Oswald, A.J. (2008). 'Is well-being U-shaped over the life cycle?', Social Science and Medicine, 66 (8), 1733-49.

Bradshaw, J. \& Millar, J. (1991) 'Lone parent families in the UK', London, Department of Social Security.

Brannen, J., Moss, P. \& Owen, C. (1997) Mothers, fathers and employment: parents and the labour market in Britain 1984-1994, Cheshire, Department for Education and Employment.

Burden, D.S. (1986) 'Single parents and the work setting: the impact of multiple job and homelife responsibilities’, Family Relations, 35 (1), 37-43.

Connelly, R. \& Kimmel, J. (2007) The impact of nonstandard work on caregiving for young children, Institute for the Study of Labor Discussion Paper No. 3093, Bonn, Institute for the Study of Labor.

Craig, L. (2005) 'The money or the care: a comparison of couple and sole parent households' time allocation to work and children', Australian Journal of Social Issues, 40 (4), 521-40. 
Craig, L. (2006) 'Does father care mean fathers share? A comparison of how mothers and fathers in intact families spend time with children', Gender and Society, 20 (2), 259-81.

Craig, L. \& Mullan, K. (2012) 'Lone and partnered mothers' childcare time within context in four countries', European Sociological Review, 28 (4), 512-26.

Dockery, A.M. (2012) 'Deriving the labour supply curve from happiness data', Economics Letters 117 (3), 898-900.

Ferrer-i-Carbonell, A. \& Frijters, P. (2004) 'How important is methodology for the estimates of determinants of happiness?', The Economic Journal, 114 (497), 641-59.

Folbre, N., Yoon, J., Finnoff, K. \& Fuligni, A.S. (2005) 'By what measure? Family time devoted to children in the United States', Demography, 42 (2), 373-90.

Gregory, R., Klug, E. \& Thapa, P.J. (2008) 'Cut-offs, knock-ons and welfare payment taper changes: an evaluation of the July 2000 tax and welfare changes for lone mothers', The Economic Record, 84 (266), 291-309.

Gronau, R. (1977) 'Leisure, home production, and work-the theory of the allocation of time revisited', Journal of Political Economy, 85 (6), 1099-1123.

Jenkins, S.P. \& O’Leary, N.G. (1995) 'Modelling domestic work time', Journal of Population Economics, 8 (3), 265-79.

Kalenkoski, C.M., Ribar, D.C. \& Stratton, L.S. (2007) 'The effect of family structure on parents' child care time in the United States and the United Kingdom', Review of Economics of the Housebold, 5 (4), 353-84.

Kelly, R.F. \& Voydanoff, P. (1985) 'Work/family role strain among employed parents', Family Relations, 34 (3), 367-74.

Kendig, S.M. \& Bianchi, S.M. (2008) 'Single, cohabitating, and married mothers' time with children', Journal of Marriage and Family, 70 (5), 1228-40.

Kristoffersen, I. (2010) 'The metrics of subjective wellbeing: cardinality, neutrality and additivity', The Economic Record, 86 (272), 98-123.

Le, A.T. \& Miller, P.W. (2010) 'The effect of children on specialization and coordination of partners' activities', Economics Letters, 108 (2), 237-41.

Le, A.T. \& Miller, P.W. (2012) 'The impact of age of children on decision making over time use in couple families', Australian Journal of Labour Economics, 15 (2), 77-100.

Le, A.T. \& Miller, P.W. (2013) 'Satisfaction with time allocations within the family: the role of family type', Journal of Happiness Studies, (forthcoming).

Lennon, M.C. \& Rosenfield, S. (1994) 'Relative fairness and the division of housework: the importance of options', American Journal of Sociology, 100 (2), 506-31. 
Piña, D.L. \& Bengtson, V.L. (1993) 'The division of household labor and wives' happiness: ideology, employment, and perceptions of support', Journal of Marriage and Family, 55 (4), 901-12.

Richards, L.N. (1989) 'The precarious survival and hard-won satisfactions of white single-parent families', Family Relations, 38 (4), 396-403.

Richards, L.N. \& Schmiege, C.J. (1993) 'Problems and strengths of single-parent families: Implications for practice and policy', Family Relations, 42 (3), 277-85,

Robinson, J.P. \& Martin, S. (2008) 'What do happy people do?', Social Indicators Research, 89 (3), 565-71.

Sanik, M.M. \& Mauldin, T. (1986) 'Single versus two parent families: a comparison of mothers' time', Family Relations, 35 (1), 53-56.

Smith, M.J. (1980) 'The social consequences of single parenthood: a longitudinal perspective', Family Relations, 29 (1), 75-81.

Summerfield, T., Young, L., Harman, J. \& Flatau, P. (2010). 'Child support and welfare to work reforms: the economic consequences for single-parent families', Family Matters, 84, 68-78.

Zick, C. \& Bryant, W. (1996) 'The new look at parents' time spent in child care: primary and secondary time use', Social Science Research, 25 (3), 260-80.

\section{Endnotes}

1. Sanik and Mauldin (1986) also drew attention to trade-offs, where lone mothers often sacrificed their time in personal care activities, including sleep and rest, to cope with the various other demands. This seemed to be associated with a clear prioritisation of time use activities, and this is a recurring theme in this line of research.

2. Folbre and colleagues (2005) defined active care as the time in which at least one adult was directly participating in an activity with a child. Passive care was defined as the time in which no adult was directly participating in an activity with the child but at least one adult was likely to be playing a supervisory role, for instance monitoring children playing outside or sleeping, preserving a safe environment, being an adult presence for children to turn to in need, and supervising games or swimming activities, including swimming lessons. Craig and Mullan (2012) distinguish 'physical care', 'talk-based care', 'accompanying a child' and 'other time with children'.

3. As noted above, some studies (Craig 2005; Folbre et al. 2005; Kendig \& Bianchi 2008) have shown that the time devoted to child care increases dramatically following consideration of secondary activities.

4. While Craig $(2005,2006)$ and others have used earlier time use surveys to illustrate the patterns in time use of many of these concepts, the links between satisfaction and these time allocation data are largely unexplored in Australia. One exception is Le and Miller (2013).

5. The family types of couple family with children and couple family without children refer to children who are resident in the household. For brevity we refer to women in couple families with children as partnered mothers, even though some women in families without resident children will also be mothers. The latter group are referred to as women in childless couples or women in families without children.

6. Note that the finding is similar to that reported by Folbre and colleagues (2005).

7. The Index of Relative Socioeconomic Disadvantage is constructed by the Australian Bureau of Statistics, using Census variables that are related to disadvantage, such as low income, low educational attainment, unemployment and dwellings without motor vehicles (ABS 2006b). Three dichotomous variables are formed to distinguish individuals living in the bottom quintile, the second-bottom quintile and the top two quintiles of areas from the reference group of individuals living in the middle quintile of areas. 
8. The approach to estimation adopted here can be viewed as an application of the model developed in Gronau's (1977) seminal study that presented a theoretical model involving choice among multiple activities.

9. Initially, separate models were estimated for each household type. However, the array of findings did not facilitate a manageable discussion. Hence the preference for the simple 'pooled-data' approach. For space reasons, only the allocations of time during weekdays are examined here.

10. It is noted that the time an individual allocates to employment-related activities is not included in the estimating equations for their other activities, as the estimated coefficients obtained under this approach could simply reflect the adding-up constraint of the time budget (Jenkins \& O’Leary 1995: 274).

11. Given the nature of the question on satisfaction with the allocation of time in the TUS, we need not be unduly concerned over the issue of causality (Robinson \& Martin 2008).

12. We also estimated a model that contained both the variables for primary time allocations and those for the secondary time allocations. This did not yield any fresh insights, and the findings are not reported. 